This item was submitted to Loughborough's Research Repository by the author.

Items in Figshare are protected by copyright, with all rights reserved, unless otherwise indicated.

\title{
Community energy storage: A smart choice for the smart grid?
}

PLEASE CITE THE PUBLISHED VERSION

https://doi.org/10.1016/j.apenergy.2017.12.056

\section{PUBLISHER}

(c) Elsevier

\section{VERSION}

AM (Accepted Manuscript)

\section{PUBLISHER STATEMENT}

This work is made available according to the conditions of the Creative Commons Attribution-NonCommercialNoDerivatives 4.0 International (CC BY-NC-ND 4.0) licence. Full details of this licence are available at: https://creativecommons.org/licenses/by-nc-nd/4.0/

\section{LICENCE}

CC BY-NC-ND 4.0

\section{REPOSITORY RECORD}

Barbour, Edward, David Parra, Zeyad Awwad, and Marta Gonzalez. 2019. "Community Energy Storage: A Smart Choice for the Smart Grid?”. figshare. https://hdl.handle.net/2134/36990. 


\title{
Community Energy Storage: A smart choice for the smart grid?
}

\author{
Edward Barbour ${ }^{\mathrm{a}}$, David Parra ${ }^{\mathrm{b}}$,Zeyad Al-Awwad ${ }^{\mathrm{c}}$, Marta C. Gonzalez*a \\ *corresponding author: martag@mit.edu \\ ${ }^{a}$ Department of Civil and Environmental Engineering, MIT, USA \\ ${ }^{b}$ Institute for Environmental Sciences, University of Geneva, Switzerland \\ ${ }^{c}$ Center for Complex Engineering Systems at King Abdulaziz City for Science and Technology and MIT, USA
}

\begin{abstract}
Energy storage can help integrate local renewable generation, however the best deployment level for storage remains an open question. Using a data-driven approach, this paper simulates 15-minute electricity consumption for households and groups them into local communities of neighbors using real locations and the road network in Cambridge, MA. We then simulate PV for these households and use this framework to study battery economics in a high PV adoption, high electricity cost scenario, in order to demonstrate significant storage adoption. We compare the results of storage adoption at the level of individual households to storage adoption on the community level using the aggregated community demands. Under the simulated conditions, we find that the optimum storage at the community level was $65 \%$ of that at the level of individual households and each $\mathrm{kWh}$ of community battery installed was $64-94 \%$ more effective at reducing exports from the community to the wider network. Therefore, given the current increasing rates of residential battery deployment, our research highlights the need for energy policy to develop market mechanisms which facilitate the deployment of community storage.
\end{abstract}

Keywords: Community energy storage, battery energy storage, distributed PV, smart energy communities, renewable energy communities

\section{Introduction}

It is well known that the generation from roof-top PV systems is not generally aligned with peak electricity loads and this can lead to limits on the proportion of solar generation that can be integrated in traditional systems [1]. Until recently this has not caused significant concern for grid operators as PV adoption rates have been low, however several factors mean this is now changing, including continual declines in the price of solar panels [2], continually increasing residential electricity prices, favorable public opinion towards solar [3] and strong government support mechanisms [4]. As a result, evermore households are installing roof-top PV systems. This has led to significant concerns regarding the over-prevalence of PV generated electricity in electricity networks $[5,6]$.

Concurrent with increasing residential electricity prices, the rewards for exported solar electricity are falling. Therefore, local PV self-consumption is gaining attention in several countries [7,8]. Energy storage is one effective way of allowing a larger fraction of de- mand to be met by PV-generation [9] and recent work has demonstrated that batteries can be used to increase the amount of PV that can be reliably integrated into the distribution network [10]. Other methods of increasing PV penetration include novel curtailment methods [11] and better PV and demand forecasting [12]. However, motivated by progress in battery development and public attention, recent studies have examined the technoeconomic impacts of PV-coupled batteries in individual dwellings, examining the required conditions for economic profitability in terms of capital expenditure as well as retail tariffs and export prices $[13,14,15]$. Together with storage for frequency control, PV-coupled batteries have become a key business area for energy storage developers, with regions such as Germany and California leading the way [16].

In contrast to storage in individual dwellings, energy storage can also be introduced for communities, i.e. Community Energy Storage (CES) [17]. The CES is then shared between members of the smart energy community, who are typically (although not exclusively) located in close proximity. Already many countries have 


\begin{tabular}{|c|c|c|c|}
\hline \multicolumn{4}{|l|}{ Nomenclature } \\
\hline Acronyms & & $J$ & within cluster sum of squares \\
\hline CES & Community Energy Storage & $K$ & number of clusters \\
\hline EAC & Equivalent Annual Cost & $\mathrm{Li}$ & battery lifetime (years) \\
\hline EAV & Equivalent Annual Value & $\mathrm{OM}$ & operation \& maintenance cost $(\$)$ \\
\hline EFC & Equivalent Full Cycles & $P^{B}$ & battery power $(\mathrm{kW})$ \\
\hline IRR & Internal Rate of Return & $P^{R, c h g}, P^{R, d i s}$ & battery rated charge/discharge $(\mathrm{kW})$ \\
\hline NPV & Net Present Value & $\begin{array}{l}S^{M} \\
S O C\end{array}$ & $\begin{array}{c}\text { monthly saving }(\$) \\
\text { battery state of charge }(\mathrm{kWh})\end{array}$ \\
\hline Subscripts & & $\begin{array}{l}S O C^{\min } / \\
S O C^{\max }\end{array}$ & $\mathrm{min} / \mathrm{max}$ battery state of charge $(\mathrm{kWh})$ \\
\hline$i$ & for the $i$-th consumer & $\triangle S O C$ & $\begin{array}{l}\text { change in battery state of charge } \\
\qquad(\mathrm{kWh})\end{array}$ \\
\hline$j$ & for the $j$-th cluster & $c_{j}$ & centroid location of the $j^{\text {th }}$ cluster \\
\hline$y$ & for the $y$-th year & capCost & total capital costs $(\$)$ \\
\hline Parameters and & Variables & $\begin{array}{l}d_{i} \\
d_{i}^{0}\end{array}$ & $\begin{array}{l}\text { demand of consumer } i(\mathrm{~kW}) \\
\text { initial demand of consumer } i(\mathrm{~kW})\end{array}$ \\
\hline$\epsilon$ & $\begin{array}{l}\text { uniformly distributed random variable } \\
\text { in the range }[-1,1]\end{array}$ & $l_{i}$ & location of consumer $i$ \\
\hline$\eta^{c h g} / \eta^{d i s}$ & $\begin{array}{c}\text { battery charging/discharging efficiency } \\
(\%)\end{array}$ & $r^{d}$ & discount rate $(\%)$ \\
\hline$\pi^{g r i d} / \pi^{e x}$ & $\begin{array}{l}\text { electricity price for the grid, for } \\
\text { exported solar }(\$ / \mathrm{kWh})\end{array}$ & $s_{i}$ & PV generation of consumer $i(\mathrm{~kW})$ \\
\hline$C_{i}$ & cost of electricity for consumer $i(\$)$ & $t$ & time period (15-minute timestep) \\
\hline$C_{i}^{P V}$ & cost of electricity with PV only (\$) & $\Delta t$ & duration of time period $t$ \\
\hline$C F_{y}$ & cash flow in year $y(\$)$ & & \\
\hline
\end{tabular}

experienced increases in "renewable energy communities", groups of neighbors motivated to reduce their energy costs and promote the development of renewable energy [18]. In general, the CES then acts as an energy management system for the community. Related to the local energy communities concept are microgrids, localised electrical systems that can operate independently from the larger grid [19]. The topic of optimizing microgrids for renewable integration has gained much attention in the last decade [20], as well as their interactions with electricity markets [21] and ability to provide demand response [22] with electric vehicles and stationary energy storage devices [23]. Recent research has also studied the optimal power flows between clusters of microgrids [24] and optimized over multiple criteria, including costs and robustness related factors [25]. While microgrids imply independent control from the wider electrical network and clear electrical boundaries, smart energy communities can form in localised sections of the main electricity system without significant autonomy.

Similar to the advantages for community renewable energy, potential advantages of CES acknowledged in the previous literature are economies of scale for batteries and benefits related to the lower likelihood of short duration consumption peaks [26]. However, a systematic comparison of batteries for individual dwellings and communities in terms of size, location, electricity flows and economic attractiveness is so far lacking and this study aims at providing insights into the optimum aggregation level of storage deployment next to the consumption centres. One particular problem in the study of smart energy communities is the lack of location data associated with openly available electricity meter data, due to privacy concerns. Therefore, in this work we simulate community formation by connecting together neighboring households along the road network and matching real monthly consumption values to data sources where 15-minute consumption is available [27]. We also simulate realistic PV generation profiles based on real PV generation data. We then use the household demand profiles or the aggregate community demand profiles to estimate an economically optimum level of storage for each household and community respectively, with the main contribution of our work being a comparison between the two storage scales. 
We utilize monthly electric bills obtained from a local electric utility in Cambridge and smart meter data from the Pecan Street project, based in Austin Texas. This provides a source of 15-minute resolution electricity data for in excess of 1000 households, as well as solar generation with the same temporal resolution for those households with rooftop PV installed [28]. Figure 1a shows the daily load and generation data for an example home on a typical April day. We define mislaignment as the proportion of a consumer's solar generation that they do not consume, as shown in Equation 1.

$$
\text { misalignment }=\frac{\mathrm{PV} \text { exported }}{\text { Total generation }}
$$

Figure $1 \mathrm{~b}$ shows the distribution of total misalignments for consumers in the Pecan Street data with PV installations for the month of April. It can be seen that the misalignment between the generation and consumption is significant and observe that the average misalignment for all homes over the month of April is 57\%, therefore only $43 \%$ of electricity they produce matches their demand. We also compare the misalignment estimated at two temporal resolutions and see that higher temporal resolutions are important for accuracy [7].


Figure 1: (a) a daily load and generation profile in April. (b) monthly misalignment values between generation and demand for all homes

The rest of this paper is structured as follows. Section 2 describes the creation of the local smart energy communities, the simulation of the 15-minute electricity consumption and PV generation, and the battery model. Section 3 gives the simulation results, including the effects of the simulated batteries and the economic results, Section 4 provides a brief discussion and Section 5 presents the main conclusions.

\section{Methods}

\subsection{Creating local smart energy communities}

To form the communities we use monthly electric bills from an electric utility in Cambridge, MA, which



Figure 2: Flow chart illustrating the community forming algorithm.

contain monthly consumption and addresses for 4574 households. Our aim is to make communities formed of groups of neighboring households, hence we join consumers along the road network. Firstly, we establish a root node for each community by clustering the address locations into 200 groups using longitude/latitude values obtained by geolocating. The clusters are formed using $k$-means and the euclidean distance metric. The $k$-means approach iteratively moves $K$ cluster centroids to minimize the objective function:

$$
J=\sum_{j=1}^{K} \sum_{i=1}^{N}\left(l_{i, j}-c_{j}\right)^{2}
$$

Here, $l_{i, j}$ is the $i$-th household location which has been assigned to the $j$-th cluster with centroid location $c_{j}$. Then, to establish root nodes for each of the communities we find the central point of the cluster and take the root node as the node closest to that point. All of the locations corresponding to the geo-located addresses are then connected to the road network available from Open Street Maps. Each community is then grown out- 
wards from the root node along the road network using a multi-source breadth-first search method based on the Dijkstra shortest path algorithm. A flow chart of the algorithm is shown in Figure 2. This aims to provide realistic communities of neighbors (Figure 3 ) formed of localised groups of households. It is also worth noting that the connections between the community members could provide an approximation for the electrical distribution network, which typically follows roads. However, this is not always the case and the exact topology of the network is not openly available due to security constraints.

\subsection{Simulating 15-minute demand and generation}

Each of the household consumers (i.e. each of the buildings) in our smart energy communities has a monthly electric consumption associated with it. Firstly, we compare the monthly consumption distributions for all households between the Pecan Street data and the Cambridge data and find that the distribution for April best matches Cambridge in July, which is likely due to the low electric cooling loads at this time in Austin. Additionally the Cambridge distributions are similar throughout the year (see Figure 4). Restricting to the month of April yields 484 Pecan households with a complete month of data. We bin both datasets into distinct monthly usage brackets and for each of the Cambridge households a Pecan Street demand profile in April in the same monthly usage bracket is randomly selected, scaling by a constant factor to match the exact Cambridge usage. Random noise of the form $d_{i}(t)=d_{i}^{0}(t)(1+0.2 \epsilon)$ is added, where $d_{i}^{0}(t)$ is the initial demand of the consumer $i$ at time $t, d_{i}(t)$ is the demand after noise has been added, $\epsilon$ is a uniformly distributed random variable in the range $[-1,1]$ and the factor of 0.2 is added to keep the demand within $20 \%$ of the Pecan Street profile.

To simulate each household's PV generation, we use the real generation profiles available in the Pecan Street data. We observe that for the Pecan Street households with PV, the distribution of the ratio between their monthly generation and consumption is best described by a lognormal probability distribution, as shown in Figure 5. Furthermore, we note by comparing solar irradiance data from the National Solar Radiation DataBase (NSRDB) [29] for the nearest weather stations that the yearly average Cambridge irradiance is closest to the February irradiance profile for Pecan Street. Therefore, for each Cambridge household we randomly select a Pecan Street PV profile in February, with the probability of accepting that selection given by the lognormal probability distribution of the ratio of generation to consumption. In this way, the Cambridge PV profiles are modeled after real PV generation profiles, and we ensure that the ratio between generation and consumption is preserved.

This leaves us with one month of simulated 15minute demand and one month of potential PV generation for the simulated households. In the rest of our work we consider that $40 \%$ of households choose to install rooftop-PV. It is important to note that since the solar adoption is random, a given community may have significantly more or less than $40 \%$ solar adoption (although we choose an adoption scenario where all communities have at least one solar installation). We find that as a result of this probabilistic adoption the solar penetration ranges from $17-80 \%$ within the individual communities, which generalizes our results to a high degree.

\subsection{Household and Community batteries}

We develop a model for lithium ion batteries for residential storage since this technology is already predominant for both residential and utility applications, given its good C-rates, no memory effect, slow calendar losses and low maintenance costs [30]. The chargedischarge equation is shown by Equation 3. $S O C(t)$ is the battery's state of charge at time $t$ and $\triangle S O C(t)$ is the change in the state of charge, which can be either positive (charging) or negative (discharging). The battery must always obey the constraints in Equations 4 and 5 . We denote the charging and discharging efficiencies of the battery as $\eta^{c h g}$ and $\eta^{d i s}$ respectively. The change in the battery's state of charge $\triangle S O C(t)$ is related to the power transfer $P^{B}(t)$ at period $t$ by Equations 6 and 7 .

$$
\begin{gathered}
S O C(t)=S O C(t-1)+\Delta S O C(t) \\
S O C^{\min } \leq S O C(t) \leq S O C^{\max } \\
P^{R, d i s} \leq P^{B}(t) \leq P^{R, c h g} \\
P^{B}(t) \Delta t \eta^{c h g}=\Delta S O C(t) \text { for } P^{B}(t), \Delta S O C(t) \geq 0 \\
\frac{P^{B}(t) \Delta t}{\eta^{d i s}}=\Delta S O C(t) \text { for } P^{B}(t), \Delta S O C(t)<0
\end{gathered}
$$

In our simulations, we assume that batteries are used to minimize the cost of either a household's or a community's total electricity. The cost of electricity at a particular time period for consumer (i.e. a household or community) $i, C_{i}(t)$, is dependent on whether the consumer is net importing or exporting at the time, and is expressed conditionally in Equations 8 and 9. 


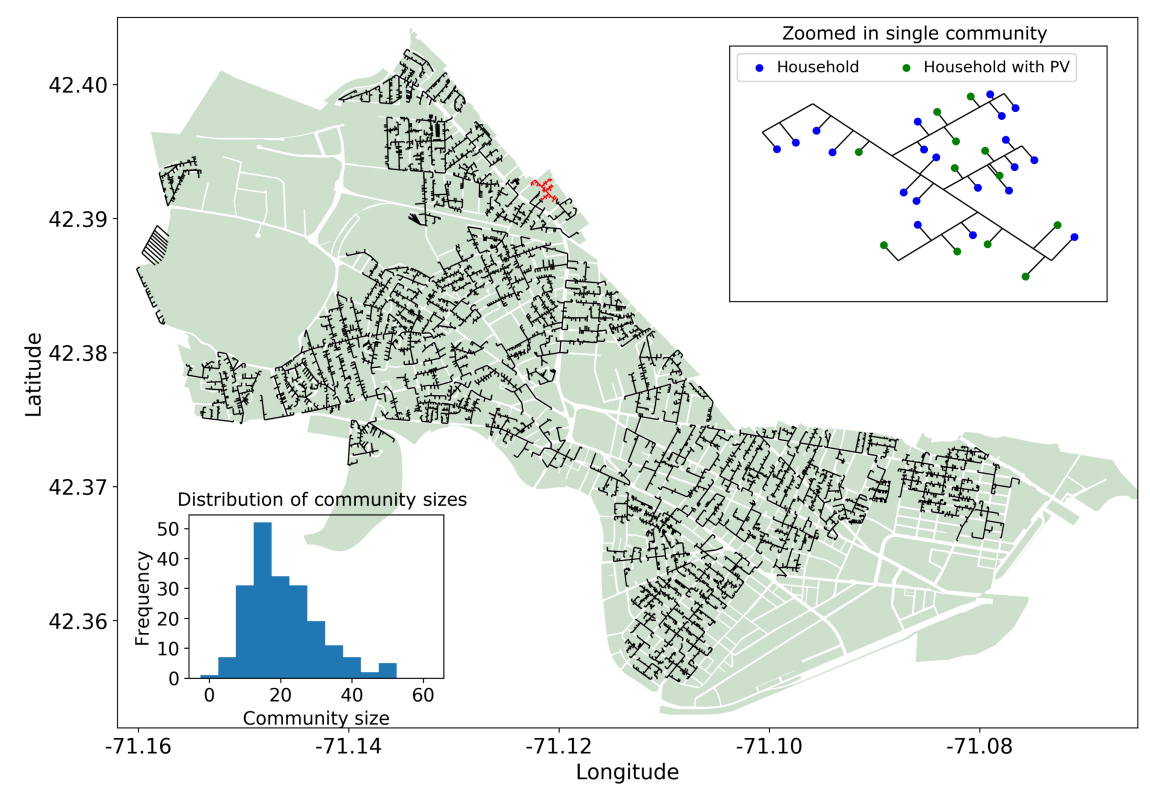

Figure 3: Illustrating the communities created. The inset at the bottom left shows the distribution of community sizes and the inset in the top right zooms in to show the local community highlighted in red.
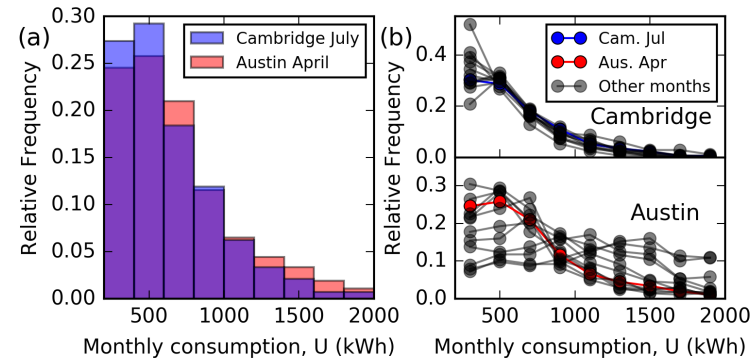

Figure 4: The distribution of monthly usage for Cambridge and Austin. (a) Cambridge in July and Austin in April. (b) Both cities in all months (2015)
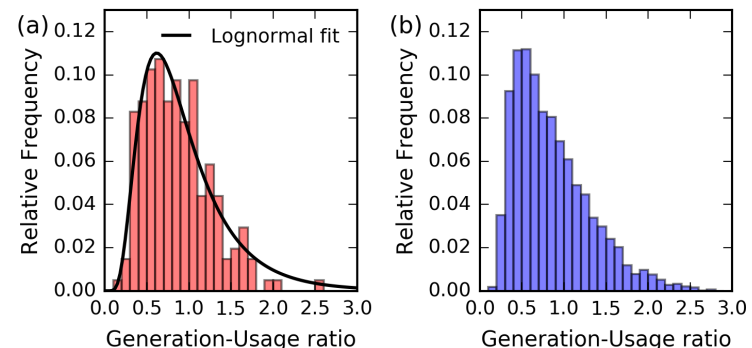

Figure 5: (a) Generation to consumption ratio for Pecan Street households fitted by a lognormal probability distribution. (b) The simulated Cambridge distribution.

$$
\begin{aligned}
& C_{i}(t)= {\left[d_{i}(t)-s_{i}(t)+P_{i}^{B}(t)\right] \Delta t \pi^{\text {grid }} } \\
& \text { for } d_{i}(t)+P_{i}^{B}(t) \geq s_{i}(t) \\
& C_{i}(t)= {\left[s_{i}(t)-\left(d_{i}(t)+P_{i}^{B}(t)\right)\right] \Delta t \pi^{e x} } \\
& \text { for } d_{i}(t)+P_{i}^{B}(t)<s_{i}(t)
\end{aligned}
$$

Here $d_{i}(t)$ is the consumer (household or community) demand at time $t, s_{i}(t)$ is any $\mathrm{PV}$ generation, $P_{i}^{B}(t)$ is the battery action and $\pi^{\text {grid }}$ and $\pi^{e x}$ are the costs for grid electricity and the reward for excess solar respectively. The battery is scheduled as framed in Equation 10 (for 1 month - i.e. 288015 minute time periods).

$$
\text { Minimize } \sum_{t=t_{1}, \ldots, t_{2880}} C_{i}(t)
$$

When considering a battery for an individual household, $d_{i}(t)$ is the electric usage of that household and $s_{i}(t)$ is their PV generation at time $t$. Surplus PV (if not stored by the household) is used by the community neighbors or exported from the community to the wider network if no neighbors require electricity. When considering a community, $d_{i}(t)$ is the sum of the demand of all households in the community and $s_{i}(t)$ is the sum of all the PV within the community at time $t$. Therefore, surplus PV from a household is first used by the neighbors before being stored or exported from the community. 


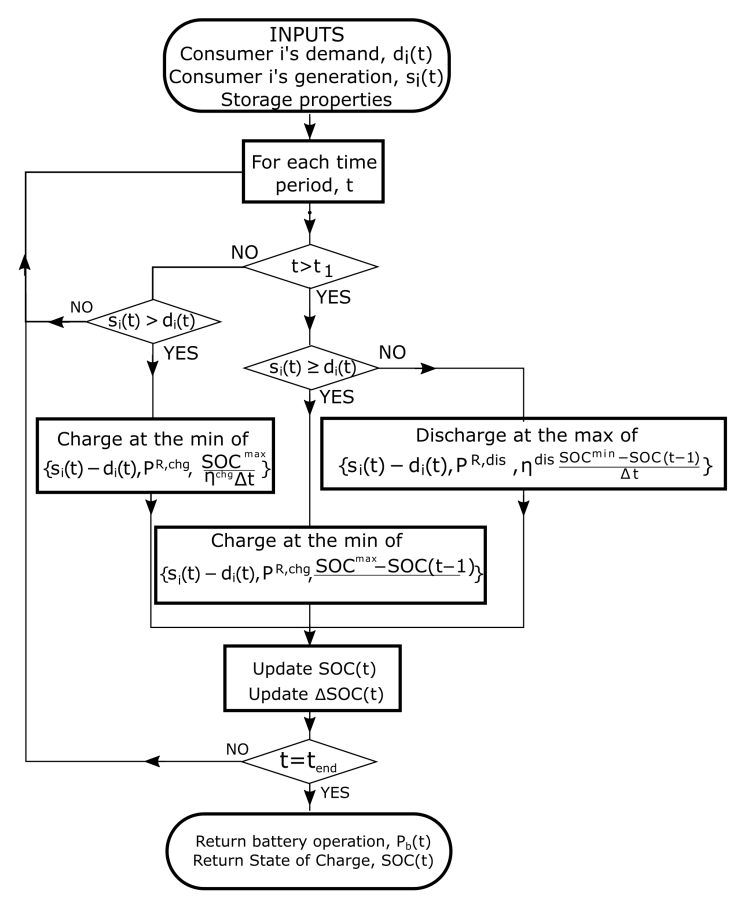

Figure 6: Flow chart depicting the battery scheduling algorithm.

Equation 10 is essentially a simple unit commitment problem with one controllable aspect - the battery. The result of the minimization in Equation 10 is then the schedule of operation of a consumer's battery which minimizes their electricity bill. We explicitly form this problem as a cost minimization to reflect the primary interest of domestic consumers for using batteries, which is to reduce their electricity costs [31] and note that this is also a primary reason in the formation of renewable energy communities [18]. This optimum schedule of battery operation depends on the electricity price $\left(\pi^{\text {grid }}\right)$ and the income per $\mathrm{kWh}$ for exporting solar to the network $\left(\pi^{e x}\right)$. If the income from solar export is lower than the price for grid electricity then consumers can reduce their electricity bill by storing electricity (forfeiting the income for PV export) and avoiding purchase from the grid by using the battery, provided the difference in prices is sufficient given the round trip efficiency of the battery - explicitly when $\pi^{\text {grid }}>\pi^{e x} /\left(\eta^{\text {chg }} \eta^{\text {dis }}\right)$. Furthermore, if $\pi^{\text {grid }}$ and $\pi^{e x}$ are constant then the optimum battery schedule from a costs minimization perspective is a strategy that charges at the maximum rate when there is solar that would otherwise be exported until the battery is fully charged and discharges when the solar generation can no longer meet all the local demand. A schematic of the algorithm to schedule the bat- tery operation is shown in Figure 6. This strategy is coincident with a strategy that maximizes the consumers self-consumption.

In the simulated month, the total saving provided by consumer $i$ 's battery is expressed by:

$$
S_{i}^{B}=\sum_{t=t_{1}, \ldots, t_{2880}} C_{i}^{P V}(t)-\sum_{t=t_{1}, \ldots, t_{2880}} C_{i}(t)
$$

In Equation 11, the first term represents the consumer's monthly electricity bill with PV-only including the income from surplus PV as calculated in Equations 8 and 9 with $P_{i}^{B}=0$. Explicitly, $C_{i}^{P V}(t)=$ $\left[d_{i}(t)-s_{i}(t)\right] \Delta t \pi^{g r i d}$ if $d_{i}(t) \geq s_{i}(t)$ and $C_{i}^{P V}(t)=-\left[s_{i}(t)-\right.$ $\left.d_{i}(t)\right] \Delta t \pi^{e x}$ if $d_{i}(t)<s_{i}(t)$. The second term in Equation 11 is the consumer's electricity bill including the PV and battery system as calculated in Equations 8 and 9. The total benefit of the battery is positive if the savings are greater than the cost over its lifetime, $\mathrm{Li}$. To assess this we use the discounted cash flow model which discounts future cash flows by the discount rate $r^{d}$, so that the time value of money is accounted for. $L i$ is estimated in years by $L i=3000 /(12 \times \mathrm{EFC})$, which assumes that each battery can perform 3000 equivalent full cycles and $\mathrm{EFC}$ is the equivalent full cycles performed during the simulated month. The Equivalent Annual Cost (EAC) of each consumer's battery is then expressed by Equation 12 .

$$
E A C_{i}=\operatorname{capCost}_{i} \frac{r^{d}\left(1+r^{d}\right)^{L i}}{\left(1+r^{d}\right)^{L i}-1}+O M_{i}
$$

$O M_{i}$ is the annual operation and maintenance cost of the battery and capCost $_{i}$ is the capital cost. Since our simulation is monthly, we extrapolate the monthly battery savings $S_{i}^{B}$ to annual values, therefore the Equivalent Annual Value is:

$$
E A V_{i}=12 \times S_{i}^{B}-E A C_{i}
$$

This is reasonable as the Cambridge demands are similar throughout the year (Figure 4b), however a key assumption is that the seasonal variations in solar are ignored. While this could be improved, this approach is an improvement on other works which have simply considered an average day [32]. We discuss the effect of using a winter month on our estimated storage viability in the results section. Additionally, while it would be preferable to use yearly data, restricting our search of the Pecan Street data to households with yearly data left significantly fewer households.

For each household or community, we consider feasible battery sizes in the range $0-250 \mathrm{kWh}$ and select 
the battery size which maximizes $E A V_{i}$ in Equation 13 . The upper range of $250 \mathrm{kWh}$ is selected based on the maximum battery size which has a positive EAV for any community. Figure 7 summarizes the process schematically.

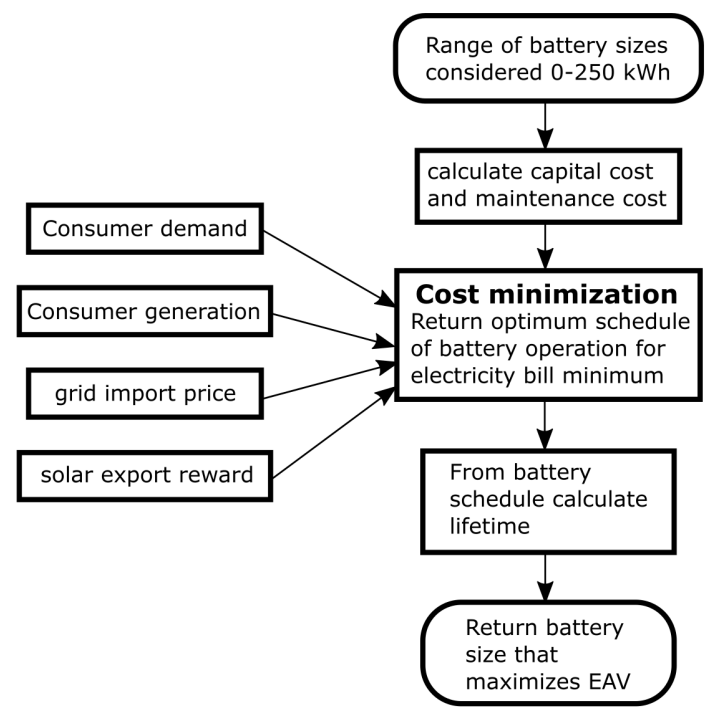

Figure 7: Summarizing the entire process for estimating the battery size which maximizes EAV for each household or community.

Finally, we then estimate the Internal Rate of Return (IRR) for each of the household and community batteries. IRR is defined as the discount rate required for the Net present Value (NPV) of the battery to be zero. The NPV is the sum of the present values of anticipated monetary flows regarding the battery over the course of its lifetime, as shown by Equation 14. Each yearly net cash flow $C F_{y}$ is the sum of the yearly cash inflows and outflows, i.e. the annual battery savings and any expenditure for that year (including capital and maintenance costs) respectively. Therefore IRR is found by solving Equation 14 for NPV= 0 .

$$
N P V=\sum_{y=0}^{y=L i} \frac{C F_{y}}{\left(1+r^{d}\right)^{y}}
$$

In order to estimate the battery cost we assume that it is composed of three main components. These include the cell costs, the inverter costs and the maintenance costs which are modeled depending on the battery size. Although Balance of Plant (BOP) costs are sometimes considered separately, many modern battery manufacturers integrate these within the cell costs that they quote. We assume cell costs of $\$ 250 / \mathrm{kWh}$, inverter costs of $\$ 500 / \mathrm{kW}$ [33] and annual maintenance costs of $\$ 10 / \mathrm{kW}$ [34]. Additionally, the inverter is sized to match the maximum charge/discharge rates of the battery and a reasonable estimate for lithium-ion batteries performing stationary applications is $0.5 \times S O C^{\max }$. This is a typical value for stationary energy storage applications - much higher C-rates have been demonstrated and are typically proposed for transport applications, however these are detrimental for cycling capacity [35]. Our battery costing model assumes that the cell stack cost increases linearly with the battery capacity but there is cost reduction with the scale for the inverter and maintenance costs. This was confirmed with several battery and inverter manufacturers and developers and based on these discussions we assume that the inverter costs scale to the power of 0.7 after $3 \mathrm{~kW}$ and the maintenance costs scale to the power of 0.6 after $10 \mathrm{~kW}$ as a first attempt to model these economies of scale. This cost model has also been used in [36]. This leads to a calculated capital cost of $\$ 6,200$ for a $14 \mathrm{kWh}$ battery and a yearly maintenance cost of $\$ 80$, and is similar to the anticipated capital cost of the $14 \mathrm{kWh} / 7 \mathrm{~kW}$ Tesla Powerwall 2 [37] (quoted at \$6,200 including the supporting hardware) and including the inverter. Figure 8 shows the battery costs as a function of the capacity.

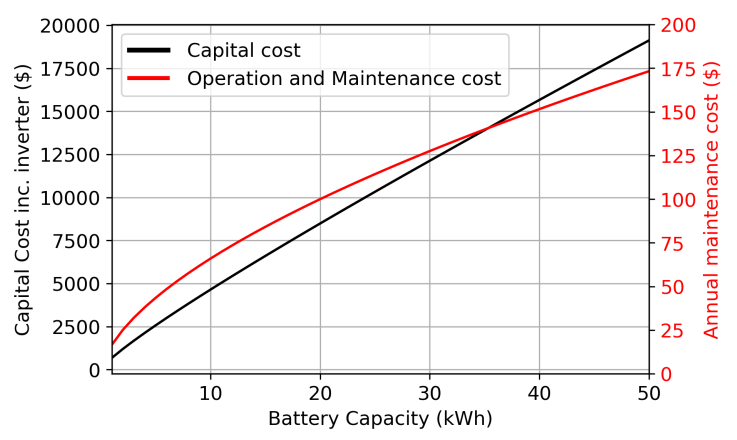

Figure 8: Capital and maintenance costs against battery size in kWh.

\subsection{Summary}

A summary of the battery properties is given in Table 1.

We assume electrical costs of $\pi^{\text {grid }}=\$ 0.35 / \mathrm{kWh}$ and that exported solar electricity is rewarded at $\pi^{e x}=\$ 0.05 / \mathrm{kWh}$. Our reasons for adopting these prices is to demonstrate a regime in which there may be significant storage adoption and because $\$ 0.05 / \mathrm{kWh}$ is a typical price level for wholesale electricity in our simulated region. It is worth noting that in 2015 the average price of residential retail electricity in Massachusetts 
Table 1: Simulated battery properties. These properties are reflective of Lithium ion batteries using nickel manganese cobalt chemistry with a typical nominal voltage of 3.6-3.7V/cell.

\begin{tabular}{|c|c|}
\hline $\begin{array}{c}\text { Property } \\
\text { cost }\end{array}$ & Value of Function \\
\hline $\begin{array}{c}\text { C-rate (charge } \\
\text { and discharge })\end{array}$ & $\$ 250 / \mathrm{kWh}$ \\
\hline $\begin{array}{c}\text { Inverter cost } \\
(3 \mathrm{~kW})\end{array}$ & $\$ 1500$ \\
\hline $\begin{array}{c}\text { Inverter cost } \\
{[\text { Inverter cost }}\end{array}$ \\
\hline $\begin{array}{c}\text { O\&M cost } \\
(10 \mathrm{~kW})\end{array}$ & $\$ 3 \mathrm{~kW})] \times([\text { Capacity }(\mathrm{kW})] / 3)^{0.7}$ \\
\hline $\begin{array}{c}\text { O\&M cost } \\
{[\mathrm{O} \& \mathrm{M} \text { cost }}\end{array}$ \\
\hline $\begin{array}{c}\text { Charging } \\
\text { efficiency }\end{array}$ & $94.8 \%$ \\
\hline $\begin{array}{c}\text { Discharging } \\
\text { efficiency }\end{array}$ & $94.8 \%$ \\
\hline $\begin{array}{c}\text { Max. allowed } \\
\text { cycle depth }\end{array}$ & $85 \%$ \\
\hline Lifetime cycles & 3000 \\
\hline
\end{tabular}

was $\$ 0.19 / \mathrm{kWh}$ and it is widely understood that at current US prices neither batteries nor PV are economic without subsidies [38, 39]. However, electricity prices all across the world are rising and in other developed nations the price of electricity is significantly higher. In Germany prices are typically around $\$ 0.36 / \mathrm{kWh}$ and in the UK the average electricity price is $\$ 0.25 / \mathrm{kWh}$. Export rewards for PV generation are also falling rapidly [13].

In all our calculations we assume a round-trip battery efficiency of approximately $90 \%$, with equal charging and discharging efficiencies. It is worth noting that in other storage technologies (for example in compressed air energy storage) charging and discharging efficiencies could be substantially different. We use a timestep $\Delta t=15$ minutes and a discount rate $r^{d}=5 \%$. When calculating the IRR we also assume that retail electricity prices rise at $2 \%$ per year and Operation and Maintenance costs $(O M)$ also rise at $2 \%$ per year.
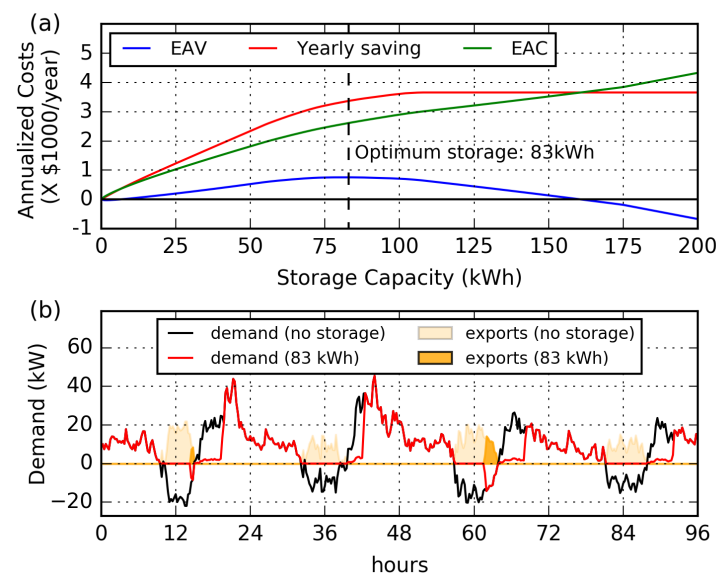

Figure 9: (a) The benefit and costs of battery against battery size. For this particular community we see that the net benefit is maximized at $83 \mathrm{kWh}$. (b) The load profile of the community with and without an $83 \mathrm{kWh}$ battery.

\section{Simulation Results}

\subsection{Optimum storage size for one community}

Figure 9 illustrates how the optimum size of battery is calculated for one community (the process is the same for each community as well as for each household). For this community, the cost of very small battery systems is greater than the potential savings, however, as the battery capacity is increased the savings introduced by the battery become greater than the costs. When this is true there is a net economic benefit to the battery. The rate of increase in the battery savings eventually decreases and subsequently intersects again with the equivalent annual cost of the battery - at this point there is no net benefit from installing storage and the annualized saving is equal to the cost. Between these two values there is a clear maximum in the EAV, which for the particular community in Figure 9 occurs at $83 \mathrm{kWh}$. We consider that the point of maximum total benefit is the optimum economic level of energy storage. Figure $9 \mathrm{~b}$ shows the effect that the $83 \mathrm{kWh}$ battery has on the load profile of the community. It is clear that the storage substantially reduces the surplus solar electricity which is exported to the wider electrical grid. However, it is not the best economic choice to store all of the surplus solar energy, as to do this would require over-sizing the battery for most of its use.

\subsection{Results for all households and communities}

Using the same approach, it is possible to calculate the optimum storage level for all of the communities as well as for all the individual households. Distributions 

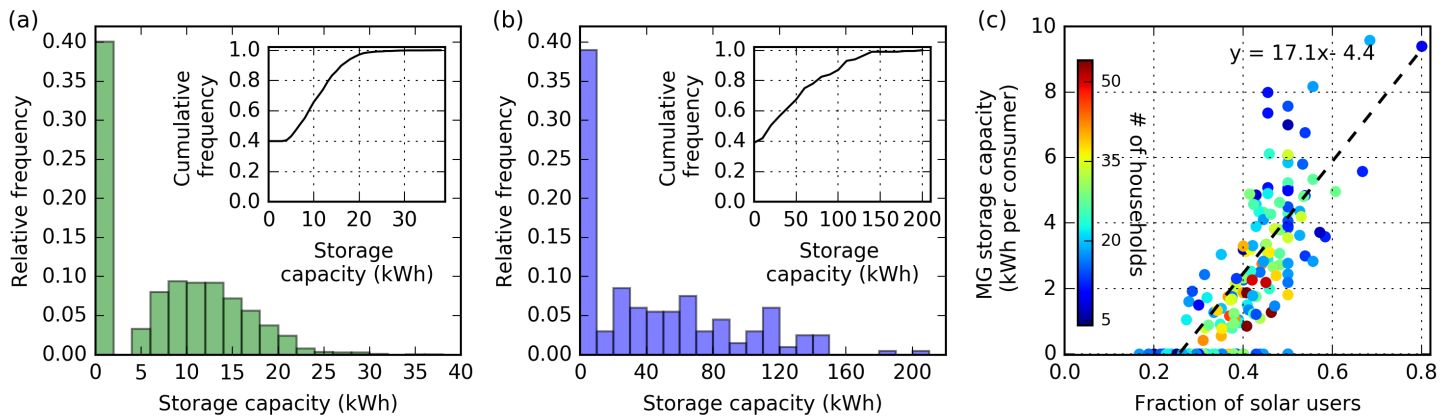

Figure 10: Distributions for the optimum battery capacities. (a) For the individual households with PV. (b) For the communities. (c) Optimum battery capacity against the fraction of households with PV.

of the optimum battery sizes are shown in Figure 10 . Although when sized for individual households the batteries installed have smaller capacities, we find that the total storage capacity installed in the household scenario is $13.0 \mathrm{MWh}$ compared to only $8.5 \mathrm{MWh}$ in the community scenario. For communities, 39\% do not require any storage due to the aggregating effect of the community (in general, communities with less than $26 \%$ PV penetration do not require storage). In addition, we find that due to higher inverter and maintenance costs per unit capacity, smaller battery systems below $4 \mathrm{kWh}$ are not found to be economic. Typically, we find the optimum capacity for households is in the $5-22 \mathrm{kWh}$ range, with the average optimum at $12 \mathrm{kWh}$. It serves as validation that this does indeed correspond to typical battery sizes available on the residential storage market. For communities, the corresponding range is much larger, spanning 5-200 $\mathrm{kWh}$, due to the different community sizes and PV penetration levels. Figure 10c shows that for communities in which it is economic to install a battery, the capacity increases by approximately $1.7 \mathrm{kWh}$ per household for a $10 \%$ increase in solar adoption.

Table 2 compares the household and community battery scenarios for the simulated month. We find that community batteries generally offer better return on investment than household batteries. We also see that for communities, the battery IRR increases as the fraction of households with PV in the community increases (see Figure 11). Considering the smart energy communities, CES is also much more effective at reducing the imports and exports between the communities and the wider grid. In total, the monthly imports for all the communities were reduced by $91 \mathrm{MWh}$, from a total of $2523 \mathrm{MWh}$ to $2432 \mathrm{MWh}$ with community batteries. This compares to a reduction of $60 \mathrm{MWh}$ with household batteries. While the total reduction in imports is small, it is informative to compare against the maximum
Table 2: Comparison of Community batteries to households batteries.

\begin{tabular}{|c|c|c|}
\hline & $\begin{array}{c}\text { Individual } \\
\text { household } \\
\text { batteries }\end{array}$ & $\begin{array}{c}\text { Commu- } \\
\text { nity } \\
\text { batteries }\end{array}$ \\
\hline $\begin{array}{c}\text { Total demand } \\
\text { (MWh) }\end{array}$ & 3244 & 3244 \\
\hline $\begin{array}{c}\text { Solar generation } \\
\text { (MWh) }\end{array}$ & 851 & 851 \\
\hline Base imports & 2523 & 2523 \\
\hline Base exports (MWh) & 130 & 130 \\
\hline $\begin{array}{c}\text { Total storage } \\
\text { capacity (MWh) }\end{array}$ & 13.0 & 8.5 \\
\hline Average IRR (\%) & 8.0 & 9.3 \\
\hline $\begin{array}{c}\text { Imports with storage } \\
\text { (MWh) }\end{array}$ & 2464 & 2432 \\
\hline $\begin{array}{c}\text { Exports with storage } \\
\text { (MWh) }\end{array}$ & 49.5 & 27.8 \\
\hline $\begin{array}{c}\text { Import reduction per } \\
\text { kWh storage (kWh } \\
\text { per kWh storage) }\end{array}$ & 4.6 & 10.7 \\
\hline $\begin{array}{c}\text { Export reduction per } \\
\text { kWh storage (kWh } \\
\text { per kWh storage) }\end{array}$ & 6.2 & 12.0 \\
\hline \multicolumn{2}{|c|}{ (M) } & \\
\hline
\end{tabular}

possible reduction. This is equivalent to the base exports - the total solar generation that is unused. Hence the community batteries reduced imports by $70 \%$ of the maximum including the losses in the battery compared to $46 \%$ with household batteries. The corresponding reduction in exports is larger in both cases - due to the efficiency loss of the battery. For community batteries this was $102 \mathrm{MWh}$ while for household batteries it was 80 MWh. These values represent $78 \%$ and $62 \%$ of the total potential reduction in exports respectively. The reduc- 
tion in exports with household batteries also does not translate directly into a reduction in the community exports, because consumers are scheduling their batteries according to their own load profile, thus they often store solar energy when it could be used by their community neighbors. This has the effect of increasing the overall community imports due to the efficiency penalty associated with the battery. Calculating the reductions per unit of storage installed further emphasizes the advantages of community batteries. Each kWh of community battery reduced the monthly imported electricity on average by $10.7 \mathrm{kWh}$ and the corresponding exports by $12.0 \mathrm{kWh}$, compared to $4.6 \mathrm{kWh}$ and $6.2 \mathrm{kWh}$ respectively for household batteries.
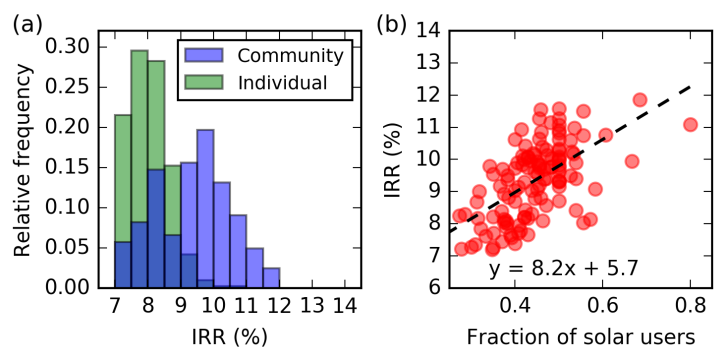

Figure 11: Internal Rates of Return for batteries. (a) For the individual households (green) and the communities (blue). (b) The IRR of community batteries against the fraction of PV households in the community.

\subsection{Sensitivity to the solar resource}

Finally, we examine the sensitivity of the results to the solar resource. To do so we model PV generation from the month of January in Cambridge, when the solar resource is significantly smaller than the yearly average. To simulate the solar PV profiles for our Cambridge households we use Pecan solar data for December. We also ensure that each Cambridge household is assigned generation data from the same Pecan PV installation as for their yearly average generation. We find that the community battery IRRs suffer significantly, with the average IRR falling from $9.3 \%$ to $4.6 \%$, whereas the corresponding reduction for household batteries is much more modest, dropping only from $8.0 \%$ to $7.1 \%$. The explanation for this is that the optimum storage size for households is generally smaller than their solar exports, and therefore even with January solar production the reduction in the use of household batteries is small. Conversely the optimum community battery capacities store much higher proportions of the excess solar production, so they are under-utilized to a much greater extent when the solar production is decreased. However, community storage was still far more effective at reducing imports and exports. This result is in agreement with a previous study which informed that the community scale helps to increase the size of the optimal battery capacity relative to the maximum storage demand, defined as the largest daily PV surplus energy throughout the year [40]. The corresponding values were an import reduction of 5.6 $\mathrm{kWh}$ and export reductions of $6.2 \mathrm{kWh}$ per $\mathrm{kWh}$ of community battery capacity installed, compared to $2.4 \mathrm{kWh}$ and $3.8 \mathrm{kWh}$ per $\mathrm{kWh}$ installed for household batteries.

\section{Discussion}

In our analysis, storage is operated to minimize the cost of a consumer's electricity, which under our assumed pricing structure is equivalent to the operation which maximizes PV self-consumption. However, there are many other applications for storage to create value. These include provision of ancillary services [41] and participation in energy markets with fluctuating prices [42], although a minimum size threshold is required for the latter [43]. One method of further incentivizing community storage could be through capacity tariffs [44] which explicitly reward the limitation of imports and exports in power terms. These tariffs are already offered by utility companies to medium and large industrial customers and are expected to become more relevant for residential consumers in future, especially with the anticipated increase in the deployment of electric vehicles and heat pumps.

This work raises questions in terms of storage ownership and operation - i.e. which parties can have a financial interest in storage. While for individual household storage it seems clear that the household owner or occupant should be able to own and operate the storage, a CES system could be community-owned, utilityowned, owned by the Distribution network operator (DNO), or owned by a combination of stakeholders. The relevant electricity tariff structure would have to account for the stakeholders involved [45]. While household consumers are offered a standard set of electricity tariff options, any CES must be negotiated on a case-bycase basis. Therefore, policy developments which introduce standardized community storage options would be invaluable in understanding the financial arguments.

It is likely that the framework we have developed is useful for other purposes. To create the local communities, we have employed aspects graph theory which has yielded estimates for the local topology of the distribution network. Each household is a connected node in the network and we have simulated electricity consumption and generation at each node in the network. It would 
serve as a validation to compare the network topology produced with a real distribution network, however this information is typically unavailable due to security concerns. If this could be done, however, then different spatial deployments of PV and storage could be studied, to find the locations in the network where benefits were maximized, for example, by minimizing line losses in the distribution network and delaying (or even avoiding) investments in infrastructure such as transformers or extra transmission capacity.

\section{Conclusions}

Our results illustrate that community energy storage has a number of advantages over household storage including, decreasing the total amount of storage deployed, decreasing surplus PV generation which must be exported to the wider network and subsequently increasing the self-sufficiency of local smart energy communities. The increase in community self-sufficiency arises from the fact that household batteries are scheduled according to the needs of the individual households, and thus often store excess solar when it could be used by neighboring households.

In terms of economic arguments, we found that IRR values were higher for community storage than for household storage. Additionally, for community storage the IRR increased with the amount of PV in the community. However, this meant that it was also more sensitive to the solar resource, suffering significantly more than household IRR if the solar resource was decreased.

Therefore finally, due to the system-wide benefits of community storage, we argue that specific market mechanisms should be developed which favor community storage deployment, especially in regions where the proportion of solar households is high or is expected to rise significantly in future. This is especially important because of the high energetic costs of batteries and the finite nature of materials required for battery manufacture. This work is timely due to the potential for a boom in household battery adoption in high solar regions.

\section{Acknowledgements}

The research was supported in part by grants from the Center for Complex Engineering Systems at KACST and MIT, the MIT Energy initiative and the Commission for Technology and Innovation in Switzerland (the project of SCCER-HaE - Swiss Competence Centre for Energy Research in Heat and Electricity Storage). The authors thank Arda Halu for useful information and help with the data preparation.

\section{References}

[1] P. Denholm, R. M. Margolis, Evaluating the limits of solar photovoltaics (PV) in traditional electric power systems, Energy Policy 35 (2007) 2852-2861.

[2] D. Feldman, G. Barbose, R. Margolis, R. Wiser, N. Darghouth, A. Goodrich, Photovoltaic (PV) Pricing Trends: Historical, Recent, and Near-Term Projections, NREL-DOE Technical Report (2012) 1-30.

[3] I. Heras-Saizarbitoria, E. Cilleruelo, I. Zamanillo, Public acceptance of renewables and the media: An analysis of the Spanish PV solar experience, Renewable and Sustainable Energy Reviews 15 (2011) 4685-4696.

[4] B. Kumar Sahu, A study on global solar PV energy developments and policies with special focus on the top ten solar PV power producing countries, 2015.

[5] P. Denholm, M. Connell, G. Brinkman, J. Jorgenson, Overgeneration from Solar Energy in California : A Field Guide to the Duck Chart, Technical Report, National Renewable Energy laboratory, 2015.

[6] M. Braun, T. Stetz, R. Bründlinger, C. Mayr, K. Ogimoto, H. Hatta, H. Kobayashi, B. Kroposki, B. Mather, M. Coddington, et al., Is the distribution grid ready to accept large-scale photovoltaic deployment? state of the art, progress, and future prospects, Progress in photovoltaics: Research and applications 20 (2012) 681-697.

[7] R. Luthander, J. Widén, D. Nilsson, J. Palm, Photovoltaic selfconsumption in buildings: A review, Applied Energy 142 (2015) $80-94$.

[8] V. Q. J. Weniger, J. Bergner, T. Tjaden, Economics of Residential PV Battery Systems in the Self-Consumption Age, 29th EU-PVSEC (2014) 3871 - 3877.

[9] V. Fthenakis, J. E. Mason, K. Zweibel, The technical, geographical, and economic feasibility for solar energy to supply the energy needs of the US, Energy Policy 37 (2009) 387-399.

[10] E. J. Palacios-Garcia, A. Moreno-Muñoz, I. Santiago, I. M. Moreno-Garcia, M. I. Milanés-Montero, Pv hosting capacity analysis and enhancement using high resolution stochastic modeling, Energies 10 (2017) 1488.

[11] R. Luthander, D. Lingfors, J. Widén, Large-scale integration of photovoltaic power in a distribution grid using power curtailment and energy storage, Solar Energy 155 (2017) 1319-1325.

[12] D. Van der Meer, J. Widén, J. Munkhammar, Review on probabilistic forecasting of photovoltaic power production and electricity consumption, Renewable and Sustainable Energy Reviews (2017).

[13] J. Hoppmann, J. Huenteler, B. Girod, Compulsive policymaking - The evolution of the German feed-in tariff system for solar photovoltaic power, Research Policy 43 (2014) 14221441.

[14] D. Parra, M. K. Patel, Effect of tariffs on the performance and economic benefits of PV-coupled battery systems, Applied Energy 164 (2016) 175-187.

[15] J. Linssen, P. Stenzel, J. Fleer, Techno-economic analysis of photovoltaic battery systems and the influence of different consumer load profiles, Applied Energy 185 (2017) 2019-2025.

[16] On the importance of reducing the energetic and material demands of electrical energy storage, Energy Environ. Sci. 6 (2013) 1083-1092.

[17] B. P. Roberts, C. Sandberg, The role of energy storage in development of smart grids, Proceedings of the IEEE 99 (2011) 1139-1144.

[18] G. Dóci, E. Vasileiadou, let s do it ourselves individual motivations for investing in renewables at community level, Renewable and sustainable energy reviews 49 (2015) 41-50. 
[19] R. H. Lasseter, P. Paigi, Microgrid: A conceptual solution, in: Power Electronics Specialists Conference, 2004. PESC 04. 2004 IEEE 35th Annual, volume 6, IEEE, pp. 4285-4290.

[20] C. Chen, S. Duan, T. Cai, B. Liu, G. Hu, Smart energy management system for optimal microgrid economic operation, IET renewable power generation 5 (2011) 258-267.

[21] M. Marzband, A. Sumper, A. Ruiz-Álvarez, J. L. DomínguezGarcía, B. Tomoiagă, Experimental evaluation of a real time energy management system for stand-alone microgrids in dayahead markets, Applied Energy 106 (2013) 365-376.

[22] H. K. Nunna, S. Doolla, Demand response in smart distribution system with multiple microgrids, IEEE Transactions on Smart Grid 3 (2012) 1641-1649.

[23] M. van der Kam, W. van Sark, Smart charging of electric vehicles with photovoltaic power and vehicle-to-grid technology in a microgrid; a case study, Applied Energy 152 (2015) 20-30.

[24] K. G. Boroojeni, M. H. Amini, A. Nejadpak, T. Dragicevic, S. S. Iyengar, F. Blaabjerg, A novel cloud-based platform for implementation of oblivious power routing for clusters of microgrids, IEEE Access (2016).

[25] V. N. Coelho, I. M. Coelho, B. N. Coelho, M. W. Cohen, A. J. Reis, S. M. Silva, M. J. Souza, P. J. Fleming, F. G. Guimarães, Multi-objective energy storage power dispatching using plugin vehicles in a smart-microgrid, Renewable Energy 89 (2016) 730-742.

[26] D. Parra, M. Swierczynski, D. I. Stroe, S. A. Norman, A. Abdon, J. Worlitschek, T. ODoherty, L. Rodrigues, M. Gillott, X. Zhang, et al., An interdisciplinary review of energy storage for communities: challenges and perspectives, Renewable and Sustainable Energy Reviews 79 (2017) 730-749.

[27] A. Halu, A. Scala, A. Khiyami, M. C. González, Data-driven modeling of solar-powered urban microgrids, Science advances 2 (2016) e 1500700.

[28] J. D. Rhodes, C. R. Upshaw, C. B. Harris, C. M. Meehan, D. A Walling, P. A. Navrátil, A. L. Beck, K. Nagasawa, R. L. Fares, W. J. Cole, H. Kumar, R. D. Duncan, C. L. Holcomb, T. F. Edgar, A. Kwasinski, M. E. Webber, Experimental and data collection methods for a large-scale smart grid deployment: Methods and first results, Energy 65 (2014) 462-471.

[29] National Renewable Energy Laboratory, National Solar Radiation Database 19912005 Update : User's Manual, Task No. PVA7.6102 (2007) 472.

[30] N. K. C. Nair, N. Garimella, Battery energy storage systems: Assessment for small-scale renewable energy integration, Energy and Buildings 42 (2010) 2124-2130.

[31] M. Graebig, G. Erdmann, S. Röder, Assessment of residential battery systems (rbs): profitability, perceived value proposition, and potential business models, in: 37th IAEE International Conference (2014), volume 25.

[32] S. X. Chen, H. B. Gooi, M. Q. Wang, Sizing of energy storage for microgrids, IEEE Transactions on Smart Grid 3 (2012) 142151.

[33] SMA Inverters, Battery Inverters, 2017.

[34] A. A. Akhil, G. Huff, A. B. Currier, B. C. Kaun, D. M. Rastler, S. B. Chen, A. L. Cotter, D. T. Bradshaw, W. D. Gauntlett, DOE/EPRI 2013 electricity storage handbook in collaboration with NRECA, Sandia National Laboratories Albuquerque, NM, 2013.

[35] N. Nitta, F. Wu, J. T. Lee, G. Yushin, Li-ion battery materials: Present and future, Materials Today 18 (2015) 252-264.

[36] A. Abdon, X. Zhang, D. Parra, M. K. Patel, C. Bauer, J. Worlitschek, Techno-economic and environmental assessment of stationary electricity storage technologies for different time scales, Energy 139 (2017) 1173-1187.

[37] Tesla Inc., Tesla Powerwall, 2017.
[38] B. P. Rand, J. Genoe, P. Heremans, J. Poortmans, Solar Cells Utilizing Small Molecular Weight Organic Semiconductors, Prog. Photovolt: Res. Appl. 15 (2007) 659-676.

[39] S. Reichelstein, M. Yorston, The prospects for cost competitive solar PV power, Energy Policy 55 (2013) 117-127.

[40] D. Parra, M. Gillott, S. A. Norman, G. S. Walker, Optimum community energy storage system for PV energy time-shift, Applied Energy 137 (2015) 576-587.

[41] C. Clastres, T. T. Ha Pham, F. Wurtz, S. Bacha, Ancillary services and optimal household energy management with photovoltaic production, Energy 35 (2010) 55-64.

[42] R. Arghandeh, J. Woyak, A. Onen, J. Jung, R. P. Broadwater, Economic optimal operation of Community Energy Storage systems in competitive energy markets, Applied Energy 135 (2014) 71-80.

[43] C. Goebel, H. A. Jacobsen, Bringing distributed energy storage to market, IEEE Transactions on Power Systems 31 (2016) 173186.

[44] M. Schreiber, P. Hochloff, Capacity-dependent tariffs and residential energy management for photovoltaic storage systems, IEEE Power and Energy Society General Meeting (2013).

[45] R. D. Masiello, B. Roberts, T. Sloan, Business models for deploying and operating energy storage and risk mitigation aspects, Proceedings of the IEEE 102 (2014) 1052-1064. 